\title{
Influence of pulmonary emphysema on COPD assessment test-oriented categorization in GOLD document
}

\author{
Toshio Suzuki' \\ Yuji Tada' \\ Naoko Kawata' \\ Jun Ikari' \\ Yasunori Kasahara' \\ Yoriko Sakurai' \\ Ken lesato' \\ Rintaro Nishimura' \\ James West ${ }^{2}$ \\ Koichiro Tatsumi ${ }^{1}$ \\ 'Department of Respirology, \\ Graduate School of Medicine, Chiba \\ University, Chiba, Japan; ${ }^{2}$ Department \\ of Medicine, Vanderbilt University \\ Medical Center, Nashville, TN, USA
}

Correspondence: Yuji Tada

Department of Respirology, Graduate

School of Medicine, Chiba University,

I-8-I Inohana Chuo-ku, Chiba 260-8670, Japan

Tel $+8|432227| 7 \mid$

Fax +8I 432262176

Email ytada@faculty.chiba-u.jp
This article was published in the following Dove Press journal:

International Journal of COPD

19 June 2015

Number of times this article has been viewed

Background: The COPD assessment test (CAT) score is a key component of the multifactorial assessment of COPD in the Global initiative for chronic Obstructive Lung Disease (GOLD) guidelines of 2014. Nevertheless, little is known regarding the differences among COPD categories in terms of clinical parameters such as pulmonary function or radiological findings. Thus, our aims in this study were to evaluate the associations between CAT scores and pulmonary clinical parameters, and to investigate factors that could discriminate between a "less symptomatic group" (categories A and C) and a "more symptomatic group" (categories B and D) among stable COPD patients.

Methods: We enrolled 200 outpatients at Chiba University Hospital. Study subjects were assessed by CAT, pulmonary function testing, and multidetector computed tomography (MDCT). We assessed possible correlations between these indices.

Results: CAT scores were negatively correlated with percentage of the forced expiratory volume in 1 second predicted value ( $\mathrm{FEV}_{1} \%$ predicted) and percentage of the diffusing capacity for carbon monoxide per liter of lung volume predicted value $\left(\mathrm{DL}_{\mathrm{CO}} / \mathrm{VA}[\%\right.$ predicted] $)$ results and positively correlated with low attenuation volume percentage (LAV\%) and residual volume to total lung capacity ratios (RV/TLC). In the "more symptomatic group" (category B or D), the mean $\mathrm{DL}_{\mathrm{CO}}$ /VA (\%predicted) was significantly lower and the mean LAV\% and RV/TLC was significantly higher than those in the "less symptomatic group" (category A or C), respectively. Interestingly, those in category B had higher mean LAV\% compared to those in category $\mathrm{C}$.

Conclusion: CAT scores were significantly correlated with pulmonary function parameters and emphysematous changes on MDCT. The new GOLD classification system would be a step toward a phenotypic approach, especially taking into account the degree of emphysema and hyperinflation.

Keywords: COPD assessment test, diffusing capacity, emphysema, residual volume ratio

\section{Introduction}

The Global initiative for chronic Obstructive Lung Disease (GOLD) documents of 2011 divide COPD patients into four categories (A, B, C, and $\mathrm{D})$ by combining symptom assessments, exacerbation history, and severity of airflow limitation. ${ }^{1-3}$ Treatment strategy is decided according to the GOLD category. Recently, several studies reported that the modified Medical Research Council (mMRC) questionnaire is relatively insensitive in evaluating the quality of life (QOL) of COPD patients compared with the COPD assessment test (CAT) ${ }^{4-6}$ Indeed, GOLD 2014 guidelines recommend that a comprehensive assessment such as the CAT should be the assessment of choice. ${ }^{7}$ Although several studies have tried to clarify the characteristics of each category classified by mMRC, ${ }^{8-11}$ little is known about the characteristics of each category classified by CAT score. 
In particular, it is unknown whether the degree of emphysema, which is a major contributor to COPD, is reflected in the categorization of the GOLD document.

As we previously reported, most COPD patients are classified as having an emphysema-dominant phenotype. ${ }^{12}$ Emphysema severity is independently associated with a rapid annual decline in forced expiratory volume in 1 second $\left(\mathrm{FEV}_{1}\right)$ in COPD. ${ }^{13}$ Therefore it may be reasonable to take into account the emphysema severity in the COPD categorization of GOLD.

The aims of present study were: 1) to analyze the associations between CAT scores and pulmonary function parameters and multidetector computed tomography (MDCT) findings and 2) to evaluate the differences between "less symptomatic" (categories A and C) and "more symptomatic" (categories B and D) categories with similar degrees of obstructive impairment.

\section{Methods}

\section{Study subjects and design}

Our study subjects included 269 consecutive patients who were diagnosed with or suspected of having clinically stable COPD at Chiba University Hospital from July 2010 through January 2015. All patients had a history of smoking. Each patient underwent pulmonary function tests (PFTs) and MDCT on the same day. COPD was diagnosed based on past history, a physical examination, and spirometric data, according to GOLD documents. ${ }^{2}$

Patients were excluded if they had no airflow obstruction by GOLD criteria ( $\mathrm{N}=25)$; obvious abnormal lung parenchymal lesions, such as interstitial pneumonia $(\mathrm{N}=14)$; lung cancer $(\mathrm{N}=10)$ or heart failure $(\mathrm{N}=4)$; and self-reported asthma $(\mathrm{N}=20) .{ }^{14}$ Finally, a total of 200 COPD patients were enrolled (Figure 1).

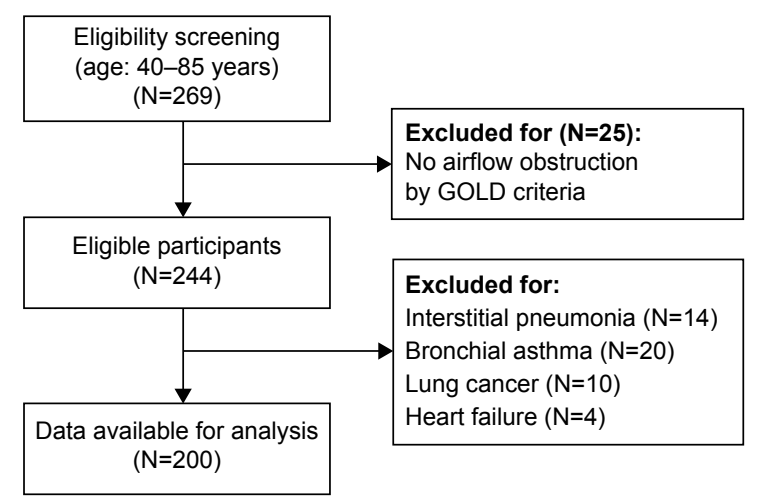

Figure I Flow chart for study participants.

Abbreviation: GOLD, Global initiative for chronic Obstructive Lung Disease.
Patients were subdivided by COPD severity according to GOLD stages I-IV, representing mild (stage I: FEV $\%$ predicted $\geq 80 \%$ ), moderate (stage $\mathrm{II}: 50 \% \leq \mathrm{FEV}_{1}$ $\%$ predicted $<80 \%$ ), severe (stage $\mathrm{III}: 30 \% \leq \mathrm{FEV}_{1}$ $\%$ predicted $<50 \%$ ), and very severe (stage IV: FEV $\%$ opredicted $<30 \%$, or $\mathrm{FEV}_{1} \%$ predicted $<50 \%$ with chronic respiratory failure present).

We also divided these patients into four categories (A, B, C, and D) according to the GOLD guidelines of $2011 .^{2}$ In short, stage I or II patients are categories A or B, while stage III and IV are categories C and D (high exacerbation history can substitute for higher stage), while those with CAT scores $\geq 10$ are in categories B or D. COPD exacerbation was defined as worsening of the disease requiring a short course of treatment with prednisolone (up to 2 weeks) alone or in combination with an antibiotic or an acute admission to the hospital because of COPD. All of these patients were clinically stable.

This study was approved by the ethics committee of Chiba University (approval number 857). Written informed consent was obtained from each participant.

\section{Clinical measurements}

After inhaling a short-acting bronchodilator, PFTs were done using a CHSTAC-8900 (Chest MI Corp, Tokyo, Japan) according to the American Thoracic Society and European Respiratory Society guidelines. ${ }^{15}$ Total lung volume and diffusion capacity were measured by helium dilution and the single-breath method, respectively. Percentage of the FEV predicted value ( $\mathrm{FEV}_{1} \%$ predicted) and percentage of the diffusing capacity for carbon monoxide per liter of lung volume predicted value ( $\mathrm{DL}_{\mathrm{CO}} / \mathrm{VA}[\%$ predicted]) were determined based on the Japanese Respiratory Society guidelines. ${ }^{16}$

All patients underwent MDCT as previously reported. ${ }^{17-19}$ The scanner was calibrated regularly with an air and a water phantom to provide for reliable measurements. No contrast medium was used. We measured MDCT parameters according to our previous report. ${ }^{19}$ All images were reconstructed using standard reconstruction algorithms, and the reconstructed images were transferred to a commercial workstation. Lung volumes with attenuation values of less than -960 Hounsfield units were segmented as low attenuation volume (LAV). The ratio of LAV to the whole lung volume was described as LAV\%.

\section{Statistical analyses}

Results are given as mean \pm standard deviations. Correlations between CAT scores, PFT parameters, and MDCT 
parameters were assessed by Spearman's rank correlation analysis. Comparison of the COPD categories (A-D) was performed using one-way factorial analysis of variance with Bonferroni correction for multiple comparisons of continuous variables. Chi-squared test was used for comparison of categorical variables. The level of significance was set at $P<0.05$. All statistical analyses were done using JMP 10.0 software (SAS Institute, Cary, NC, USA).

\section{Results}

\section{Patient characteristics}

The general characteristics of the 200 stable COPD patients are shown in Table 1. The majority of these patients were male, and their mean age was $69.8 \pm 7.9$ years. These patients had a mean smoking history of $51.8 \pm 36.0$ packyears, a mean $\mathrm{FEV}_{1}$ of $1.72 \pm 0.59 \mathrm{~L}$, a mean $\mathrm{FEV}_{1}$ \%predicted of $63.9 \% \pm 19.8 \%$, and a mean inspiratory LAV\% of $6.21 \% \pm 8.83 \%$.

The mean CAT score for these 200 patients was 9.6 \pm 7.1 .

\section{CAT scores significantly correlate with PFT, MDCT, and MDCT parameters in aggregate}

CAT scores were negatively correlated with $\mathrm{FEV}_{1}$ \%predicted values $(r=-0.372, P<0.0001)$ (Figure $2 \mathrm{~A}$ ) and $\mathrm{DL}_{\mathrm{CO}} /$ VA (\%predicted) $(r=-0.383, P<0.0001)$ (Figure 2B). With regard to MDCT findings, CAT scores were positively correlated with $\mathrm{LAV} \%$ values $(r=0.450, P<0.0001)$ (Figure 2C). Correlation $r$ values did not significantly change using variations on these metrics, including raw $\mathrm{FEV}_{1}$ values, ratio of $\mathrm{FEV}_{1}$ to forced vital capacity $\left(\mathrm{FEV}_{1} / \mathrm{FVC}\right)$, or ratio of residual volume to total lung capacity (RV/TLC).

\section{Patient characteristics in each COPD category}

Table 2 shows the clinical characteristics for patients in each COPD category. There were no significant differences in body mass index or sex between these categories. Compared with category $\mathrm{A}$, the mean $\mathrm{DL}_{\mathrm{CO}} / \mathrm{VA}$ (\%predicted) was significantly lower $(83.3 \% \pm 16.2 \%$ vs $69.7 \% \pm 19.4 \%$, $P<0.0001)$ and the mean RV/TLC was significantly higher $(38.1 \% \pm 5.17 \%$ vs $41.7 \% \pm 4.50 \%, P<0.0001)$ in category $\mathrm{B}$. As compared with category $\mathrm{C}$, for category $\mathrm{D}$, the mean $\mathrm{DL}_{\mathrm{CO}} / \mathrm{VA}$ (\%predicted) was significantly lower $(80.0 \% \pm 18.7 \%$ vs $59.5 \% \pm 25.4 \%, P=0.005)$ and the mean $\mathrm{RV} / \mathrm{TLC}$ was significantly higher $(44.8 \% \pm 4.39 \%$ vs $50.9 \% \pm 4.89 \%, P<0.0001)$. With regard to radiological findings, compared to category A or C, for category B or D, the mean inspiratory LAV\% was significantly higher (A vs B: $2.27 \% \pm 3.92 \%$ vs $7.58 \% \pm 6.54 \%, P<0.0001, \mathrm{C}$ vs D: $3.37 \% \pm 3.35 \%$ vs $15.2 \% \pm 14.0 \%, P=0.004)$.

\section{Comparison between categories $B$ and $C$}

A recent study reported that patients in category $\mathrm{B}$, characterized by more severe dyspnea, had significantly poorer

Table I Patient baseline clinical characteristics

\begin{tabular}{|c|c|c|c|c|c|}
\hline & \multicolumn{4}{|c|}{ GOLD staging } & \multirow{2}{*}{$\begin{array}{l}\text { Total population } \\
(\mathbf{N}=\mathbf{2 0 0})\end{array}$} \\
\hline & I $(\mathrm{N}=\mathbf{4 0})$ & II ( $N=$ | 07) & III $(\mathbf{N}=40)$ & IV $(\mathbf{N}=\mid 3)$ & \\
\hline Age, years & $68.9 \pm 7.2$ & $68.7 \pm 7.8$ & $73.6 \pm 7.9$ & $70.5 \pm 6.1$ & $69.8 \pm 7.9$ \\
\hline Smoking, pack-years & $47.3 \pm 30.2$ & $49.0 \pm 37.6$ & $55.3 \pm 33.4$ & $77.2 \pm 36.3$ & $51.8 \pm 36.0$ \\
\hline $\mathrm{BMI}, \mathrm{kg} / \mathrm{m}^{2}$ & $23.2 \pm 2.19$ & $23.2 \pm 3.53$ & $22.9 \pm 2.95$ & $20.4 \pm 3.52$ & $22.9 \pm 3.26$ \\
\hline Male sex, \% & 87.5 & 82.2 & 95.0 & 100 & 87.0 \\
\hline Current smokers, \% & 22.5 & 20.6 & 17.5 & 15.4 & 20.0 \\
\hline CAT score & $6.8 \pm 4.3$ & $8.7 \pm 6.6$ & $10.9 \pm 6.7$ & $21.8 \pm 5.9$ & $9.6 \pm 7.1$ \\
\hline Frequent exacerbator, \% & 2.5 & 5.6 & 17.5 & 61.5 & 11.0 \\
\hline $\mathrm{FEV}, \mathrm{L}$ & $2.46 \pm 0.27$ & $1.77 \pm 0.40$ & $1.12 \pm 0.25$ & $0.85 \pm 0.13$ & $1.72 \pm 0.59$ \\
\hline FEV (\%predicted), \% & $89.4 \pm 7.63$ & $66.4 \pm 12.1$ & $42.5 \pm 5.10$ & $30.6 \pm 7.34$ & $63.9 \pm 19.8$ \\
\hline FVC, L & $3.83 \pm 0.47$ & $3.03 \pm 0.61$ & $2.45 \pm 0.69$ & $2.45 \pm 0.40$ & $3.04 \pm 0.75$ \\
\hline $\mathrm{FEV}_{1} / \mathrm{FVC}, \%$ & $64.6 \pm 5.22$ & $58.0 \pm 7.98$ & $47.2 \pm 10.2$ & $33.6 \pm 6.83$ & $55.6 \pm 11.3$ \\
\hline $\mathrm{DL}_{\mathrm{co}} / \mathrm{VA}$ (\%predicted), \% & $80.7 \pm 16.4$ & $76.9 \pm 19.5$ & $74.2 \pm 21.0$ & $42.0 \pm 22.5$ & $74.7 \pm 21.5$ \\
\hline $\mathrm{RV} / \mathrm{TLC}, \%$ & $34.1 \pm 4.33$ & $41.3 \pm 4.59$ & $48.5 \pm 5.08$ & $52.1 \pm 5.31$ & $42.2 \pm 6.82$ \\
\hline LAV, \% & $1.26 \pm 1.84$ & $4.75 \pm 6.14$ & $7.80 \pm 9.66$ & $24.2 \pm 14.2$ & $6.21 \pm 8.83$ \\
\hline
\end{tabular}

Notes: Plus-minus values are mean \pm SD. Other values are number $(\%)$.

Abbreviations: BMI, body mass index; CAT, chronic obstructive pulmonary disease assessment test; $\mathrm{DL}_{\mathrm{co}} / \mathrm{VA}$ (\%predicted), percentage of the diffusing capacity for carbon monoxide per liter of lung volume predicted value; FEV , forced expiratory volume in I second; FEV, (\%predicted), percentage of the FEV , predicted value; FVC, forced vital capacity; FEV /FVC, ratio of FEV /FVC; GOLD, Global initiative for chronic Obstructive Lung Disease; LAV, low attenuation volume; RV/TLC, ratio of residual volume to total lung capacity; SD, standard deviation. 


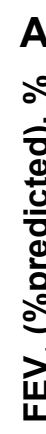

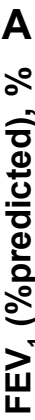
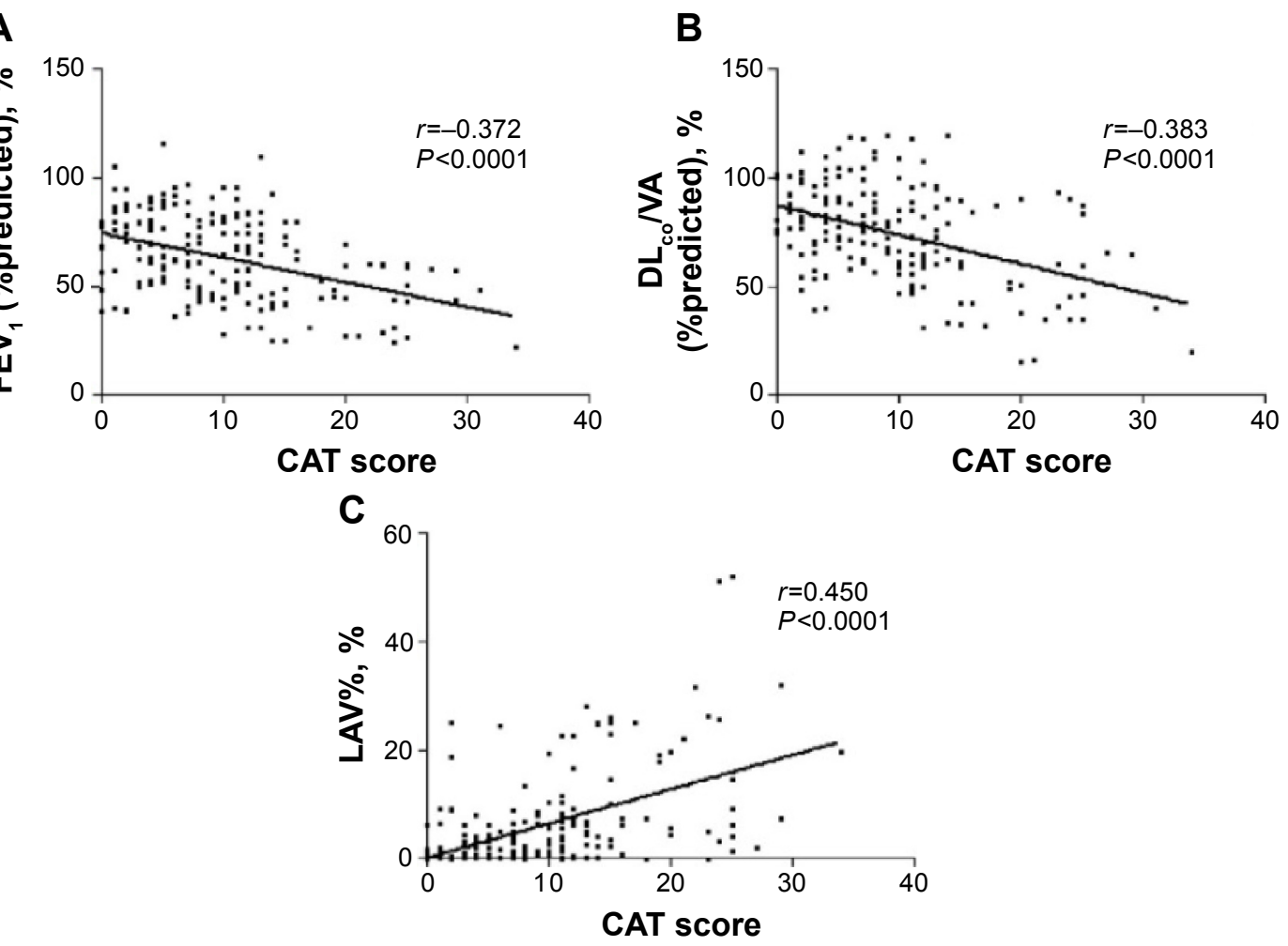

Figure 2 Correlations between CAT scores and PFT parameters and MDCT parameters.

Notes: (A) Correlation between CAT score and FEV (\%predicted). (B) Correlation between CAT score and DL $/ \mathrm{CA}^{\mathrm{VA}}$ (\%predicted). (C) Correlation between CAT score and LAV\%.

Abbreviations: CAT, chronic obstructive pulmonary disease assessment test; $\mathrm{DL}_{\mathrm{co}} / \mathrm{VA}$ (\%predicted), percentage of the diffusing capacity for carbon monoxide per liter of lung volume predicted value; FEV (\%predicted), percentage of the FEV, predicted value; LAV\%, low attenuation volume percentage; FEV I second; PFT, pulmonary function test; MDCT, multidetector computed tomography.

survival than group $\mathrm{C}$, despite having a higher $\mathrm{FEV}_{1}$ level. ${ }^{10}$ We compared these categories with regard to pulmonary functions and MDCT findings.

Patients in category B had significantly higher LAV\% results (category B vs C: $7.58 \% \pm 6.54 \%$ vs $3.37 \% \pm 3.35 \%$, $P=0.004)$ than those in category C (Table 2).

\section{Discussion}

Among stable COPD patients, CAT scores were negatively correlated with airflow limitation and diffusing capacity and positively correlated with the extent of emphysema and lung hyperinflation results. We also attempted to determine those factors that might discriminate between a "less symptomatic group" and a "more symptomatic group" based on the new GOLD assessment proposal for COPD guidelines. ${ }^{2}$ For those patients with similar degrees of airflow limitation (category A vs B and category C vs D), among the variables we investigated, a "less symptomatic group" (CAT scores of $<10$ ) and a "more symptomatic group" (CAT scores of $\geq 10$ ) could be distinguished based on their differences in $\mathrm{DL}_{\mathrm{CO}} / \mathrm{VA}$ (\%predicted) and $\mathrm{RV} / \mathrm{TLC}$ results. In addition, the extent of emphysematous changes on CT was also significantly associated with a higher CAT score. Taken together, these results suggest that a reduced diffusing capacity and lung hyperinflation are two possible causes for the significantly impaired QOL among COPD patients at the same stage of this disease. To the best of our knowledge, ours is the first report to establish a relationship between CAT scores and these COPD-related disease variables.

Another novel and interesting finding this study provides is that category $\mathrm{B}$ has a more emphysematous nature than category $\mathrm{C}$. Lange et $\mathrm{a}^{10}$ demonstrated that patients in category B had poorer survival than those in categories A and C, probably due to their higher incidence of cardiovascular disease and cancer. Our present study was cross-sectional in nature, and our results cannot be used to predict the relationship between symptoms and prognosis. However, when the effects of these comorbidities are excluded, diffusing capacity and hyperinflation may be associated with patients' impaired QOL, and category B has more emphysematous features than category A or C. This might lead to high mortality in category $\mathrm{B}$, considering that $\mathrm{CT}$ findings of emphysema predict mortality in COPD. ${ }^{20}$ Both Lange et $\mathrm{al}^{10}$ and Agusti et al ${ }^{8,9}$ 
Table 2 Patient clinical characteristics in each COPD category

\begin{tabular}{|c|c|c|c|c|c|}
\hline & $\begin{array}{l}\text { Category A }(\mathbf{N}=\mathbf{8 6}) \\
\text { mean } \pm \text { SD }\end{array}$ & $\begin{array}{l}\text { Category B }(\mathrm{N}=54) \\
\text { mean } \pm \mathrm{SD}\end{array}$ & $\begin{array}{l}\text { Category C }(\mathrm{N}=2 \mathrm{I}) \\
\text { mean } \pm \mathrm{SD}\end{array}$ & $\begin{array}{l}\text { Category } D(N=39) \\
\text { mean } \pm \text { SD }\end{array}$ & P-value \\
\hline \multirow[t]{2}{*}{ Age, years } & $\Gamma$ & ** & 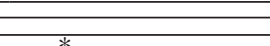 & 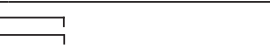 & \\
\hline & $68.0 \pm 7.3$ & $69.1 \pm 8.0$ & $72.2 \pm 8.8$ & $72.2 \pm 7.1$ & 0.001 \\
\hline Smoking, pack-years & $44.4 \pm 27.8$ & $56.3 \pm 45.1$ & $48.7 \pm 30.6$ & $63.5 \pm 36.6$ & 0.031 \\
\hline $\mathrm{BMI}, \mathrm{kg} / \mathrm{m}^{2}$ & $23.3 \pm 2.45$ & $22.9 \pm 4.12$ & $23.1 \pm 2.45$ & $22.2 \pm 3.63$ & 0.213 \\
\hline Male sex, \% & 84.9 & 79.6 & 95.2 & 94.9 & 0.077 \\
\hline & & $* *$ & & & \\
\hline VC, L & $3.4 I \pm 0.64$ & $3.3 \mathrm{I} \pm 0.73$ & $\begin{array}{c}2.80 \pm 0.75 \\
\text { *.* } \\
\end{array}$ & $\stackrel{2.8 I \pm 0.63}{\longrightarrow}$ & $<0.0001$ \\
\hline & & $* *$ & 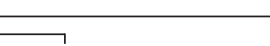 & & \\
\hline FVC, L & $3.29 \pm 0.64$ & $\begin{array}{c}3.22 \pm 0.73 \\
\longleftarrow\end{array}$ & $\begin{array}{c}2.44 \pm 0.75 \\
\sqrt[*]{* *}\end{array}$ & $\stackrel{2.55 \pm 0.61}{\longrightarrow}$ & $<0.0001$ \\
\hline FEV (\%predicted), \% & $74.5 \pm 16.2$ & 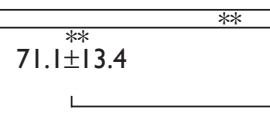 & $\underset{4}{46.8 \pm 11.6}$ & $39.8 \pm 9.95$ & $<0.0001$ \\
\hline $\mathrm{DL}_{\mathrm{co}} / \mathrm{VA}$ (\%predicted), \% & $83.3 \pm 16.2$ & $69.7 \pm 19.4$ & $80.0 \pm 18.7$ & $59.5 \pm 25.4$ & $<0.0001$ \\
\hline$R V, L$ & $2.08 \pm 0.46$ & $\underbrace{* *}_{2.42 \pm 0.40}$ & $2.54 \pm 0.72$ & 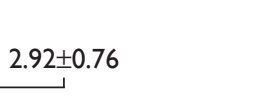 & $<0.0001$ \\
\hline TLC, L & $5.66 \pm 0.93$ & $5.75 \pm 0.95$ & $5.73 \pm 1.47$ & $5.83 \pm 1.26$ & 0.650 \\
\hline RV/TLC, \% & $38.1 \pm 5.17$ & $\mathrm{Al}^{* * 7 \pm 4.50}$ & $\begin{array}{ll}44.8 \pm 4.39 \\
* *\end{array}$ & $50.9 \pm 4.89$ & $<0.0001$ \\
\hline LAV, \% & $2.27 \pm 3.92$ & $\overbrace{7.58 \pm 6.54}$ & $3.37 \pm 3.35$ & $15.2 \pm 14.0$ & $<0.0001$ \\
\hline
\end{tabular}

Notes: Values are mean \pm SD. Other values are number $(\%)$. $* P<0.05 ; * *<<0.01$

Abbreviations: BMI, body mass index; COPD, chronic obstructive pulmonary disease; $\mathrm{DL}_{\mathrm{co}} / \mathrm{VA}$ (\%predicted), percentage of the diffusing capacity for carbon monoxide per liter of lung volume predicted value; FEV (\%predicted), percentage of the FEV, predicted value; FVC, forced vital capacity; LAV, low attenuation volume; RV, residual volume; $\mathrm{SD}$, standard deviation; TLC, total lung capacity; RV/TLC, ratio of residual volume to total lung capacity; VC, vital capacity; FEV , forced expiratory volume in I second.

suggested that higher symptoms in category B may originate from comorbidities and not from airflow limitation. In addition to their hypothesis, we proposed that emphysematous change may be another factor that determines the patient's prognosis. The GOLD classifications might still need modification for the assessment of emphysema and risk in future.

Our results are not consistent with the past cohort, which reported that low attenuation area in $\mathrm{CT}$ increased from categories $\mathrm{A}-\mathrm{B}$ to $\mathrm{C}-\mathrm{D}{ }^{8}{ }^{8}$ This inconsistency might result from the different QOL evaluation system used. They used $\mathrm{mMRC}$ for categorization, which reflects only one aspect of COPD (ie, breathlessness), while we used the CAT, which is more comprehensive. ${ }^{21}$ Han et al ${ }^{21}$ compared the mMRC and St George's Respiratory Questionnaire scores (as a surrogate of CAT) and concluded that the distribution of the four categories was significantly different. They reported that use of mMRC resulted in more patients being placed into categories $\mathrm{A}$ and $\mathrm{C}$. There are similar reports that describe differences in distributions of COPD categories when CAT or mMRC are used. ${ }^{22-25}$
As our study uses CAT rather than mMRC in categorization, it is a better match for the GOLD 2014 recommendations than were previous studies.

We also have to take note of the low frequency of acute exacerbations in this study. In the present study, patients were in the clinic every 1-2 months, and so it is unlikely that we failed to detect exacerbations. However, previous studies reported that Japanese experience fewer exacerbations. ${ }^{26,27}$ Considering the GOLD document, which classifies COPD patients with exacerbation history, it is unsurprising that distributions and characteristics of each COPD category vary from region to region.

There were limitations to our study. First, our sample size was small because this study was conducted in a single facility, though reproducibility in analyzing by MDCT and PFT is warranted. Second, the majority of our COPD patients were in categories A and B, due to institutional bias. However, although there are some limitations, our findings are of significance because association between COPD category and severity of the emphysematous lesion was clarified. 


\section{Conclusion}

CAT scores were significantly associated not only with airflow limitation, but also with diffusing capacity, lung hyperinflation, and radiographic emphysema among stable COPD patients. In a similar situation of airflow limitation, reducing diffusing capacity and lung hyperinflation are the two possible causes that impair patient's QOL. When using the CAT for categorization, a "less symptomatic group" (CAT scores of $<10$ ) and a "more symptomatic group" (CAT scores of $\geq 10$ ) can be distinguished based on their differences in emphysema or hyperinflation. In addition, the use of CAT for categorization reveals that GOLD category B might have more emphysematous findings than category $\mathrm{C}$.

\section{Acknowledgments}

We wish to thank to Mrs Akiko Moriya (Chiba University) and Mrs Saori Hiruta (Chiba University) for technical assistance. This work was supported in part by a grant to the Respiratory Failure Research Group from the Ministry of Health, Labor and Welfare of Japan.

\section{Author contributions}

All authors contributed toward data analysis, drafting and revising the paper and agree to be accountable for all aspects of the work.

\section{Disclosure}

Dr Tatsumi reports grants from Boehringer Ingelheim Japan, Inc., Pfizer, Inc., and Astellas, Inc. outside this work. The authors report no other conflicts of interest in this work.

\section{References}

1. Kim S, Oh J, Kim YI, et al. Differences in classification of COPD group using COPD assessment test (CAT) or modified Medical Research Council (mMRC) dyspnea scores: a cross-sectional analyses. BMC Pulm Med. 2013;13:35.

2. Global Initiative for Chronic Obstructive Lung Disease (GOLD). Global Strategy for the Diagnosis, Management, and Prevention of Chronic Obstructive Pulmonary Disease: Revised 2011. Available from: http:// www.goldcopd.org/uploads/users/files/GOLD_Report_2014_Jun11.pdf. Accessed February 12, 2015.

3. Vestbo J, Hurd SS, Agustí AG, et al. Global strategy for the diagnosis, management, and prevention of chronic obstructive pulmonary disease: GOLD executive summary. Am J Respir Crit Care Med. 2013;187:347-365.

4. Jones PW. The COPD Assessment Test: what have we learned over its first 5 years? Eur Respir J. 2014;44(4):833-834.

5. Jones PW, Adamek L, Nadeau G, Banik N. Comparisons of health status scores with MRC grades in COPD: implications for the GOLD 2011 classification. Eur Respir J. 2013;42(3):647-654.

6. Holt S, Sheahan D, Helm C, Tofield C, Corin A, Kocks JW. Little agreement in GOLD category using CAT and mMRC in 450 primary care COPD patients in New Zealand. NPJ Prim Care Respir Med. 2014; 24:14025.
7. Global Initiative for Chronic Obstructive Lung Disease. Global Strategy for the Diagnosis, Management and Prevention of Chronic Obstructive Pulmonary Disease. Available from: http://www.goldcopd.org/uploads/ users/files/GOLD_Report_2014_Jun11.pdf. Accessed February 12, 2015.

8. Agusti A, Hurd S, Jones P, et al. FAQs about the GOLD 2011 assessment proposal of COPD: a comparative analysis of four different cohorts. Eur Respir J. 2013;42:1391-1401.

9. Agusti A, Edwards LD, Celli B, et al. Characteristics, stability and outcomes of the 2011 GOLD COPD groups in the ECLIPSE cohort. Eur Respir J. 2013;42(3):636-646.

10. Lange P, Marott JL, Vestbo J, et al. Prediction of the clinical course of chronic obstructive pulmonary disease, using new GOLD classification: a study of the general population. Am J Respir Crit Care Med. 2012; 186(10):975-981.

11. Soriano JB, Alfageme I, Almagro P, et al. Distribution and prognostic validity of the new Global Initiative for Chronic Obstructive Lung Disease grading classification. Chest. 2013;143(3):694-702.

12. Tatsumi K, Kasahara Y, Kurosu K, et al. Clinical phenotypes of COPD: results of a Japanese epidemiological survey. Respirology. 2004; 9(3):331-336.

13. Nishimura M, Makita $H$, Nagai $K$, et al. Annual change in pulmonary function and clinical phenotype in chronic obstructive pulmonary disease. Am J Respir Crit Care Med. 2012;185(1):44-52.

14. Thomsen M, Nordestgaard BG, Vestbo J, Lange P. Characteristics and outcomes of chronic obstructive pulmonary disease in never smokers in Denmark: a prospective population study. Lancet Respir Med. 2013;1: 543-550.

15. American Thoracic Society/European Respiratory Society Task Force. Standards for the Diagnosis and Management of Patients with COPD. Version 1.2. New York, NY: American Thoracic Society; 2004. Available from: http://www.thoracic.org/clinical/copd-guidelines/resources/ copddoc.pdf\#search $=\% 2713$. + American + Thoracic + Society $+\% 2 \mathrm{~F}+$ Eur opean+Respiratory+Society+Task+Force $\% 3 \mathrm{~A}+$ Standards+for+the+Di agnosis+and+Management+of+Patients+with+COPD.+Version+1.2.+ New+York $\% 3 \mathrm{~A}+$ American+Thoracic+Society $\% 3 \mathrm{~B}+2004 \% 27$. Accessed February 12, 2015.

16. Committee of Respiratory Physiology in Japanese Respiratory Society. [Guideline of respiratory function tests-spirometry, flow-volume curve, diffusion capacity of the lung]. Nihon Kokyuki Gakkai Zasshi. 2004;Suppl:1-56. Japanese.

17. Matsuura Y, Kawata N, Yanagawa N, et al. Quantitative assessment of cross-sectional area of small pulmonary vessels in patients with COPD using inspiratory and expiratory MDCT. Eur J Radiol. 2013; 82:1804-1810.

18. Yahaba M, Kawata N, Iesato K, et al. The effects of emphysema on airway disease: correlations between multi-detector $\mathrm{CT}$ and pulmonary function tests in smokers. Eur J Radiol. 2014;83:1022-1028.

19. Yanagawa N, Kawata N, Matsuura Y, et al. Effect of threshold on the correlation between airflow obstruction and low attenuation volume in smokers assessed by inspiratory and expiratory MDCT. Acta Radiol. 2015;56(4):436-446.

20. Haruna A, Muro S, Nakano Y, et al. CT scan findings of emphysema predict mortality in COPD. Chest. 2010;138(3):635-640.

21. Han J, Dai L, Zhong N, Young D. Breathlessness or health status in chronic obstructive pulmonary disease: the impact of different definitions. COPD. 2015;12(2):115-125.

22. Grzelewska-Rzymowska I, Patora-Mikołajczyk J, Górski P. Stratification of patients with COPD according to the 2011 GOLD report. Pneumonol Alergol Pol. 2014;82(5):415-421.

23. Casanova C, Marin JM, Martinez-Gonzalez C, et al. New GOLD classification: longitudinal data on group assignment. Respir Res. 2014; 15:3.

24. Jones PW, Nadeau G, Small M, Adamek L. Characteristics of a COPD population categorised using the GOLD framework by health status and exacerbations. Respir Med. 2014;108(1):129-135. 
25. Price DB, Baker CL, Zou KH, Higgins VS, Bailey JT, Pike JS. Realworld characterization and differentiation of the Global Initiative for Chronic Obstructive Lung Disease strategy classification. Int J Chron Obstruct Pulmon Dis. 2014;9:551-561.

26. Suzuki M, Makita H, Ito YM, Nagai K, Konno S, Nishimura M; Hokkaido COPD Cohort Study Investigators. Clinical features and determinants of COPD exacerbation in the Hokkaido COPD cohort study. Eur Respir J. 2014;43(5):1289-1297.
27. Motegi T, Jones RC, Ishii T, et al. A comparison of three multidimensional indices of COPD severity as predictors of future exacerbations. Int J Chron Obstruct Pulmon Dis. 2013;8:259-271.

International Journal of COPD

\section{Publish your work in this journal}

The International Journal of COPD is an international, peer-reviewed journal of therapeutics and pharmacology focusing on concise rapid reporting of clinical studies and reviews in COPD. Special focus is given to the pathophysiological processes underlying the disease, intervention programs, patient focused education, and self management protocols.

\section{Dovepress}

This journal is indexed on PubMed Central, MedLine and CAS. The manuscript management system is completely online and includes a very quick and fair peer-review system, which is all easy to use. Visit http://www.dovepress.com/testimonials.php to read real quotes from published authors.

Submit your manuscript here: http://www.dovepress.com/international-journal-of-chronic-obstructive-pulmonary-disease-journal 